\title{
Shell beads and social behaviour in Pleistocene Australia
}

\author{
Jane Balme \& Kate Morse*
}

Why did Palaeolithic people wear shells, and why was the practice so widespread in the world? The authors' own researches in Western Australia show that specific marine shells were targeted, subject to special processes of manufacture into beads and that some had travelled hundreds of kilometres from their source. Whether they were brought in land by the manufacturers, or by specially ornamented people, these beads provided a symbolic language that somehow kept the early peoples of Australia in touch with the sea.

Keywords: Palaeolithic, Pleistocene, Australia, marine shells, ornament, beads, symbolism

\section{Introduction}

Personal ornament has long been recognised as a hallmark of modern human behaviour (d'Errico et al. 2005; Mellars 2005), and beads and pendants are among the oldest unambiguous evidence of its use. In the Old World, evidence for the age, raw materials, standardised manufacturing techniques and the distance that some beads have been found from their original source, has been used to suggest that they were made with a preconceived final product in mind for a particular aesthetic effect and were perhaps involved in long distance trade. Pleistocene Australian beads with the same characteristics can be argued to be equally significant for the early human occupation of Australia.

\section{Distribution and age of the earliest beads}

At Qafzeh Cave in the Levant ochre stains have been identified on one of five perforated shells found in a burial context associated with a thermoluminescence date of 92000 years BP (Taborin 2003). While there is some controversy over whether these shells are beads, there is no doubt that they were handled by humans (Bar-Yosef Mayer 2005). To date, the oldest unequivocal beads in the world have been recovered from two distinct phases in Middle Stone Age (MSA) deposits at Blombos Cave on the southern Cape shoreline of South Africa (d'Errico et al. 2005). The phase in which this group of 41 perforated estuarine tick shells (Nassarius kraussianus) were found has been dated to about 76000 years ago by OSL of sediments and thermoluminescence of burnt lithics (Henshilwood et al. 2004). There are other claims of MSA beads and pendants but they have been recovered as isolated finds, such as a bone pendant from Grotte Zouhra in Morocco (Debéneth 1994). Claims for even older beads have recently been made for three modified shells from Es-Skul in

* Archaeology, School of Social and Cultural Studics, University of Western Australia, Australia

Received: 23 June 2005; Accepted: 27 February 2006; Revised: 5 April 2006

ANTIQUITY 80 (2006): 799-811 
Israel and Oued Djebbana in Algeria (Vanhaeren et al. 2006). Other MSA sites with beads such as the Cave of Hearths in South Africa are undated or the context is questionable. The manufacture of ostrich shell beads is widespread in the African LSA (see McBreaty \& Brooks 2000: 521-4) particularly after 40000 years BP (Ambrose 1998: 388). They are present in Enkapune ya Muto, Kenya from about 37-40 000 years (Ambrose 1998) and are of a similar age at Kisese II rock shelter Tanzania.

In the Levant, ornaments including beads and pendants, almost all made of small mollusc shells, are abundant particularly from the Upper Palaeolithic (Bar-Yosef Mayer 2005) and have been dated from about 40000 years ago at Ksar 'Akil in Lebanon and Uçagizli in Turkey (Kuhn et al. 2001). Beads made of ostrich and estuarine shells have also been reported from an Upper Palaeolithic site in Patne, India (Sali 1989).

In Europe, ornaments are infrequent in Middle Palaeolithic sites and their association with Neanderthals is controversial. Some of the oldest are from Bacho Kiro Cave in Bulgaria, where two pierced animal teeth, dated by radiocarbon to over 43000 years old, are associated with an early Aurignacian assemblage (Kozlowski 2000). In Western Europe the dating is very controversial but the oldest claim for ivory beads is for 40000 years BP from the Aurignacian German Swabian Jura sites (Conard \& Bolus 2003) although Zilhăo and d'Errico (2003 cited in d'Errico et al. 2005) consider 36000 to be a more plausible date for these. While not found in all Aurignacian sites, bead and pendant ornaments become widespread across Europe after this time.

\section{Materials and manufacturing techniques associated with early beads}

Available evidence indicates that mollusc shells were the first materials used to manufacture beads. The oldest beads from Blombos Cave in Africa and from Ksar 'Akil and Uçagizli in the Levant are made of estuarine and marine shell. During the LSA the use of ostrich shell is particularly widespread in bead assemblages. Although European Aurignacian beads are made of a variety of material including bone, ivory and steatite (White 1993) about a third are made of pierced marine, freshwater and fossil shells (Taborin 1993). Choices of raw material vary regionally, for example, fox canines were preferred for beads made from animal teeth in France, Germany and Russia, while in Mladec in the Czech Republic, beaver incisors were the favourite (White 1993: 280) and in the Levant the selection of mollusc species for bead making varies between sites (Bar-Yosef Mayer 2005: 177).

As White (1992: 549) has noted these early beads, especially shells, were frequently manufactured from materials exotic to the region in which they are found. The majority of the shells in French sites come from the Atlantic coast which, during full glacial times, was up to $250 \mathrm{~km}$ from some sites (Taborin 1993: 218). The absence of intact unmodified beads from these deposits suggests that the beads, or perhaps the ornaments they were used for, were made elsewhere and brought to the site as complete items.

There is clear evidence that people were selective in the materials that they used to make beads. This is especially true for shells where fewer than a dozen species make up 90 per cent of several hundred known beads from the Aurignacian (White 1992: 550). In a study of the shell ornaments of the French Aurignacian and Périgordian of France, Taborin (1993) found that people clearly selected particular species notably periwinkles, dogwinkles, turret shells 
and Dentaliidae species (tusk shells) for ornaments. Both cultures used fossil and modern Atlantic and Mediterranean shells and both continued to use the same species as ornaments. In other words there seems to be a long and continuing tradition of the use of decorative ornaments and by implication a recognised aesthetic or cultural value. The main difference between the two periods is the proportions of different species used. Dentaliidae species (Tusk shells) were used by both cultures and became increasingly popular in the later periods of the Upper Palaeolithic (Taborin 1993: 221). They were the most common shells used for body ornamentation by the people who made Solutrean assemblages (Taborin 1993: 216).

This selectivity of particular shell species for ornaments is also evident elsewhere. In the Levant sites of Ksar 'Akil and Uçagizli, for example, Kuhn et al. (2001) report that a variety of mollusc shells were used as ornaments but at both sites the Palaeolithic inhabitants used the same taxa for ornamental purposes and selected comparatively rare varieties that are brightly coloured, have arresting patterns or have luminous qualities (Kuhn et al. 2001: 7642). At both sites the ranges of taxa used for ornaments are different from those used for eating. The ornamental gastropods, most of which have holes drilled through them, are much smaller than the food species (Kuhn et al. 2001: 7643). This preference for small shells for ornamental purposes is also evident in the shell assemblages dated between 36000 and $9000 \mathrm{BP}$ at the Italian site Riparo Mochi (Stiner 1999). On the other hand d'Errico et al. (2005) have argued that the MSA beads from Blombos Cave were deliberately chosen for their large size. This selection of particular species and particular sizes for ornamental purposes is evidence that the crafters of these beads had a particular aesthetic effect in mind when making the beads.

White $(1992 ; 1993)$ describes a variety of manufacturing techniques designed to contend with the differing demands of the raw materials being modified as ornaments. Techniques reported for making beads from ivory, bone and steatite include incising and then snapping around the incision made on a rod of raw material to form blanks that are then thinned and gouged, and segmenting rods that were subsequently perforated before being detached (White 1992: 550-4; 1993: 280-3). White (1989: 377, 382) has pointed to the degree of size standardisation of many of the ivory, bone and steatite beads produced in this way. For beads that were substantially altered in shape, those shapes were also often standardised. For example, ostrich shell beads made from shell fragments that were pierced and then ground to similar round shapes have been recovered from Enkapune Ya Muto shelter in Kenya and are dated to about 40000 years (Ambrose 1998: 384; Figure 3).

\section{Interpretation of the earliest beads}

Beads are a form of body ornament that, like other body ornaments including body modification, are a form of non-verbal communication indicating social value or difference. Exactly what that difference is, is difficult to tell. They may communicate social identity, such as group membership, gender or marital status or a state of being such as grief, marriage, marriage availability or some combination of these. Wobst (1977) has pointed out that visual displays of information through, for example, ornaments are often signals to strangers or infrequently encountered individuals about identity. He suggests that in these circumstances 
the meaning of the beads must be shared by the wearers and whoever they encounter or there is little point in wearing them.

This argument has been used to suggest that ornament-wearing might arise at times when the chances of meeting strangers and the benefits of advertising one's identity is high (Kuhn et al. 2001). Many researchers (e.g. Gamble 1999; Shennan 2001) have suggested that the explosion of symbolic behaviour associated with the Middle to Upper Palaeolithic transition, including the use of ornaments and exchange of exotic materials over long distances, is linked to increases in population densities. These arguments can be summarised by White's (1982) proposition that low density hominin groups who rarely came in to contact with each other would not need symbolic inventions. The distance over which shell has been traded or carried would support the notion of inter-group contact at least for the Aurignacian. Ambrose (1998: 388), too, has suggested that ostrich shell beads found from about 40000 years ago in Africa may indicate the beginnings of systems of gift giving and exchange.

\section{Pleistocene beads in Australia}

Although it is generally agreed that the first Australians were anatomically modern humans (e.g. Stringer 2001), Australians are still arguing about how long before 40000 years ago the first people arrived. Most would probably accept that the first Australians arrived sometime around about 45000 years ago (e.g. O'Connell \& Allen 1998) but some would allow dates of up to 60000 years BP (e.g. Roberts et al. 1994). There are now sites in nearly all regions of Australia dated to well over 30000 years. Symbolic behaviour is represented by such evidence as painted rock dated to 40000 years in the Kimberley (O'Connor \& Fankhauser 2001) and ritual burial practices at Lake Mungo in New South Wales (Bowler et al. 1970; Bowler \& Thorne 1976).

In general the oldest radiocarbon dated deposits in Australia are those with the best preservation of organic remains. This is hardly surprising given the link between organic remains and ${ }^{14} \mathrm{C}$ dating. Some of the best sequences spanning over 30000 years are from three sites in Western Australia, Devil's Lair, Mandu Mandu Creek rockshelter and Riwi (Figure 1). All of these sites have Pleistocene evidence for symbolic behaviour including ochre and beads.

At Devil's Lair three beads made from polished segments of macropod fibulae found in different stratigraphic horizons are dated to between about 12000 and 19000 BP (Dortch 1979). They are associated with stone artefacts and mammal remains, many of which represent the remnants of peoples' meals. Beads from the other two sites are made of marine shell and, as they are associated with dates of 30000 years BP or older, they are comparable to the early European beads.

\section{The Mandu Mandu beads}

Mandu Mandu Creek rockshelter is a small limestone cave in the western foothills of the Cape Range on the central coast of Western Australia. In 1989, 22 cone shells (Conus sp.) and fragments, all deliberately modified as beads, were recovered from the basal occupational horizon of a single $1 \mathrm{~m}^{2}$ excavation. Dating to $>32000$ years BP, 


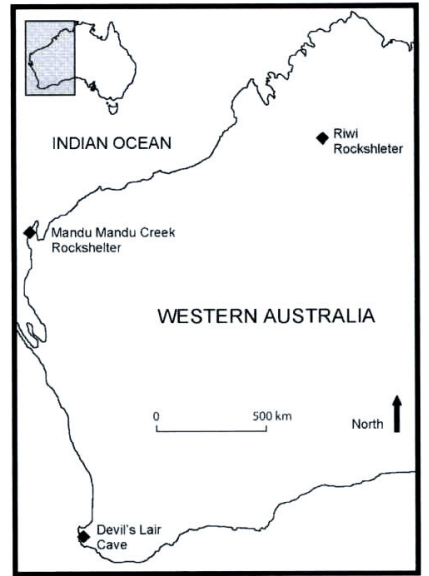

Figure 1. Location of Pleistocene bead sites mentioned in the text. the majority of the shells derived from residue excavated from the two western quadrants of the excavation at a depth of between $82-91 \mathrm{~cm}$ below the floor surface (Morse 1993).

Two distinct forms of cone shell beads are present and shown in Figure 2(a). Six of the shells are intact but have had their apex perforated and their internal structure removed to form a hollowed out shell with a round hole at the top (Figure $2 \mathrm{~b}$ ). The largest of these have a length of $21.1 \mathrm{~mm}$ and a maximum diameter of $12.4 \mathrm{~mm}$. A small notch worn into the edge of the shell at the posterior end of the aperture is clearly visible on the two best preserved whole shells (Figure 2c). In some species of cone notches occur naturally in this position. The edges of the notches on the modified shells are, however, abraded and growth lines visible on the shell surface under high magnification $(40 \times)$ appear to have been

cut or worn through by the notches. The simplest explanation for this is that the notch has been worn into the shell margin by a string on which the beads were threaded. Comparison of notches on similarly threaded ethnographic shell artefacts held in the Western Australia Museum collection show analogous wear patterns.

The second type of bead is a shell ring made from a section of the spire of each shell. As with the whole shells the apex of the shell rings has been perforated and a rounded hole formed. The result is a shell ring between 2.9 and $9.6 \mathrm{~mm}$ long (mean length $6.3 \mathrm{~mm}$ ) and between 7.2 and $12.7 \mathrm{~mm}$ in diameter (mean diameter $10.06 \mathrm{~mm}$ ) Some of the shell rings are partially broken; measurements are the maximum that could be taken.

Modifying Conus sp. shells to make beads like this is a two part process. First, the weakest part of the shell, the apex, needs to be removed perhaps by piercing or by rubbing on an abrasive stone surface, and then the internal structure broken. This can be done by inserting a fine stick into the hole and twisting it around. As a result of this action the edge of the hole in the shell apex becomes smoothed and rounded. The pierced and hollowed shell can now be threaded on a string. It is unknown if the shell rings represent deliberate additional modification of the whole shell or are an inadvertent result of mishandling of the structurally weakened shell during bead manufacture. While the apex on some modern and fossil cone shells is perforated, the resulting hole appears irregular and has a fine jagged edge. Significantly, in all the specimens examined, the internal structure of the natural shells is more or less intact. All the shells show evident selection for size and genera. They are provisionally identified as Conus dorreensis a species which typically lives in shallow waters on reef platforms and in sand under rocks, environments consistent with the predominantly 

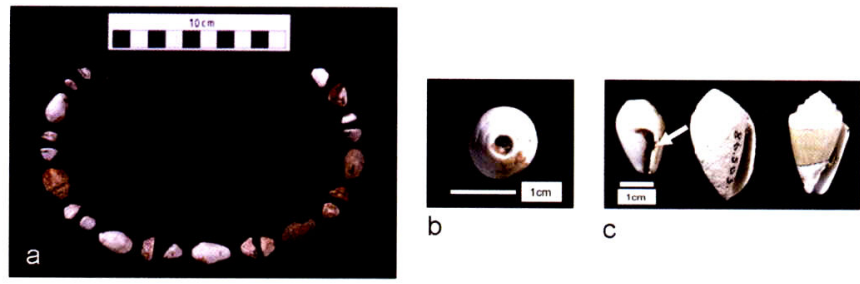

b

C

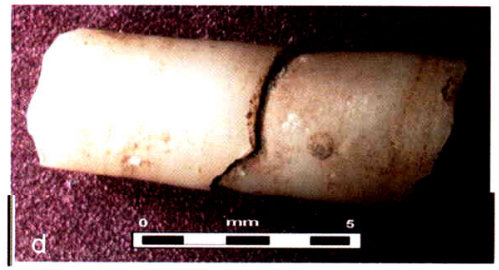

e
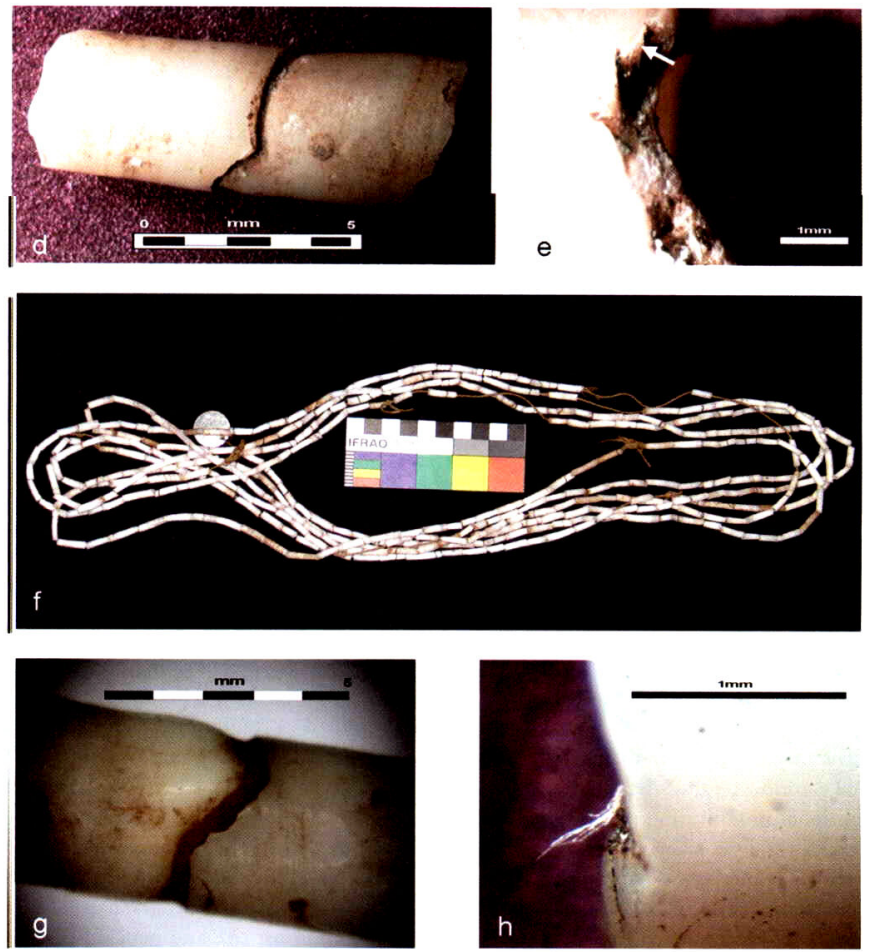

Figure 2. For legend see facing page. 


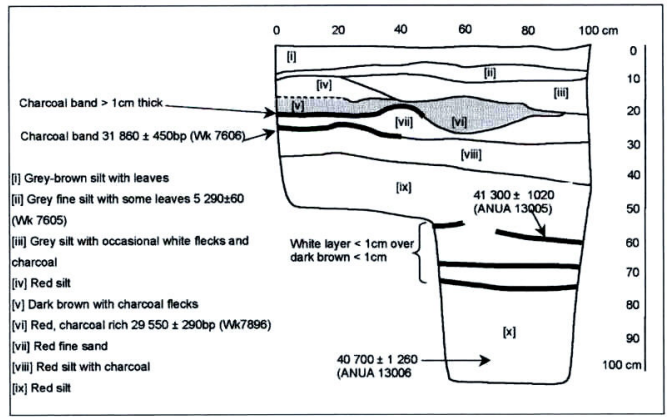

Figure 3. East section of Riui excavation.

reefed shoreline of the western coast of the Cape Range Peninsula. Shell collectors today actively seek cone shells. With over 300 known species, they belong to one of the most diverse shell families in Australian waters (Wells \& Bryce 2000). Their coloured and patterned appearance makes them a distinctive addition to shell collections and they are frequently used to make shell necklaces and other decorative ornaments. It seems not unlikely that 32000 years ago the shells at this site were selected for similar reasons.

In this context, the presence in later Pleistocene layers at Mandu Mandu Creek rockshelter of ochre and fragments of scaphopod (tusk shell) and pearl shell (Pinctada spp.), material typically associated with human decoration should be noted. Three other fragments of cone shell were also recorded in layers provisionally dated at $c .21000 \mathrm{BP}$. While equivocal, this evidence may point to a continuing tradition of decorative use of marine shell at this site.

\section{Riwi}

Ten shell beads were excavated from Riwi, a small shelter in a Devonian limestone formation in the Kimberley of Western Australia. All are fragments of tusk shells belonging to the order Dentaliidae but, as none of the fragments include the posterior part of the shell, it is not possible to further classify the shells beyond saying that they could represent eight species within the families Dentaliidae, Fustiariidae and Laevidentaliidae (G. Kendrick pers. comm.). All were recovered at depths between 15 and $25 \mathrm{~cm}$ below the surface (stratigraphic units iii, iv, v \& vi in Figure 3) and are associated with radiocarbon dates of about

Figure 2. a) Mandu Mandu shell beads in hypothetical arrangement. b) perforated apex of Mandu Mandu shell bead. c) Mandu Mandu shell bead with marked position of worn notch compared to a fossil and modern shell of the same species. d) Riwi bead with residue embedded in groove. e) End of Riwi bead showing 'chattering. f) Strand of Scaphopoda beads collected in 1899 from Kimberley Aboriginal people (Western Australian Museum A674). g) Museum bead with residue embedded in groove. b) Fibre on end of Riwi bead. 
30000 years. Associated archaeological material includes stone artefacts, ochre, bone and freshwater mussel shell (Balme 2000). These excavation units are below a clear hiatus in deposition between stratigraphic layers ii and iii. Evidence for reduced occupation and sedimentation during the last glacial maximum (LGM) has been widely documented in central and north-western Australia (O'Connor \& Veth 2006). The impact of the LGM is likely to have been felt much earlier in Australian desert areas where there is evidence of reduction in surface water availability by 35000 years ago (Hiscock \& Wallis 2004).

The Riwi beads are made on shell fragments ranging in size from $5.2-17.55 \mathrm{~mm}$ with a mean of $12.5 \mathrm{~mm}$. Most are longer than $10 \mathrm{~mm}$. The fragments used are from the anterior (or non tapering) end of the tusk shell - only one shows any curvature or tapering. Some have sinuous grooves around their circumference in one or two places along their length. These are common on modern scaphopoda and are natural in origin.

A residue, visible to the naked eye, is present within the sinuous grooves and on rough surface areas of the shells, notably the broken ends. Under a microscope $\times 50$ this residue is dark red/black (Figure 2d). A Hemastix test on two of these residue parches yielded positive 'small' results suggesting that there may be some blood in the residue.

A study of dentalium breakage by Vanhaeren and d'Errico (2003) has shown that different manufacturing techniques result in different characteristics to the fractured end of the shell. Openings on unbroken dentalium have regular edges and the posterior ends are thin and sharp. Fractured dentalium have irregular edges created by micro chipping. Fractures are either perpendicular or oblique to the main axis of the fragment and often have a lip-like morphology. Sawing produces ends with two facets. One is oblique and covered with traces left by the to-and-fro movement of the cutting edge. The break resulting from sawing leaves a facet perpendicular to the main axis that is morphologically similar to the one produced by snapped shell. The fractured ends on the beads from Riwi display a variety of morphologies including straight fractures, notched fractures and undulations. One bead has a straight and an undulating end interpreted as the result of rubbing against stringing thread. One fracture exhibits chattering suggesting sawing (Figure $2 \mathrm{e}$ ). These combinations indicate that the beads were produced by a combination of snapping and cutting. It is possible that some shells produced more than one bead.

Scaphopoda beads are still made in coastal parts of the Kimberley today. In 1983 Moya Smith of the Western Australian Museum recorded a Bardi woman making a series of dentalium shell beads by placing an intact shell on a stone anvil and then applying pressure with the back of a knife to the shell which she then snapped along the knife edge. The shells were considered to be too delicate to be directly cut with the knife. Opaque rings form along the length of scaphopoda shells and it may be along these that the shell can be cleanly snapped. The rings may represent change in the crystalline structure of the shell relating to seasonal or other factors determining their growth (S. Slack-Smith pers. comm).

The Western Australian Museum holds a large collection of ethnographic strings of scaphopoda shell beads from the Kimberley. Many of these are very long (about $4 \mathrm{~m}$ ) consisting of hundreds of beads strung on short strands of fibre and secured at both ends by small knots, which are then tied together to form a single long strand. All beads are made of fragments of anterior parts of the shell. Many of these beads were cleaned before they 
were accessioned by the museum but ochre preserved on the rough outer parts of the beads, in sinuous grooves and in the cut edges is common. Ochre appears as a dark red-brown residue and the similarity to the Pleistocene beads is remarkable. We conclude that the Riwi residues are likely to be ochre.

By way of comparison to the Riwi beads we recorded the sizes of beads on a string collected by Tunney in the Kimberley in 1899. This circular string is made up of 342 beads threaded on eight strings (between $340 \mathrm{~mm}$ and $1225 \mathrm{~mm}$ ) tied together (Figure $2 \mathrm{f}$ ). We measured 50 of these beads from one continuous strand. Bead length ranges from $8.5-21 \mathrm{~mm}$ with a mean length of $15.3 \mathrm{~mm}$. This is a little longer than the Riwi beads. The string is twisted natural fibre but the species from which it is made is not recorded. Dark red-brown ochre residue is visible on the beads (Figure $2 \mathrm{~g}$ ). It is reasonable to expect that the Riwi beads would have been strung on similar fibre. A fibre fragment was observed on the end of one the Pleistocene beads (Figure $2 \mathrm{~h}$ ).

The use of ochre as part of body painting and as colour for decorative items by Aboriginal people is well documented and is a continuing cultural tradition. The ochre noted on dentalium shell beads in both the Western Australian Museum collections and at Riwi may have been part of the original bead decoration or may have been deposited as a result of the beads being worn during activities that involved personal ornamentation and body decoration. This might explain the 'small' positive Hemastix result for the Riwi bead residue although further testing is needed to confirm this.

Although scaphopods are sub-tidal they are frequently found as empty shells on the coast and wash up on the shore in huge numbers following tropical storms (Wells \& Bryce 2000). Riwi is currently $300 \mathrm{~km}$ inland and, 30000 years ago would have been at least $500 \mathrm{~km}$ from the nearest sea. Such inland finds are not isolated in the Kimberley. Scaphopod beads have also been recovered from Carpenter's Gap Shelter 1, a cave in the same Devonian formation but about $200 \mathrm{~km}$ west of Riwi. The chronology appears to be similar but the precise age of the shell beads is not yet available (O'Connor 1995). It is worth noting, however, that even at today's sea levels this site is over $100 \mathrm{~km}$ from the coast.

\section{Discussion}

Shell beads are one part of a suite of evidence for symbolic behaviour found in the Australian Pleistocene record (see Brumm \& Moore 2005) that together illustrate the consistency of behaviours and the importance of body ornaments associated with anatomically modern humans throughout the world. Indeed, it has been suggested that symbolic behaviours were necessary for the successful colonisation of a new continent (e.g. Davidson \& Noble 1992a, 1992 b; Balme \& Bowdler in press).

The shell beads discussed here point to an apparently widespread and continued use of marine shell in the manufacture of decorative ornaments in Pleistocene Western Australia. Three aspects of the bead manufacturing process indicate an investment in time and labour to ensure a standardised ornament that, in turn, suggests the importance of the beads to their users. First, the shell species used were collected specifically for ornament making. In both sites discussed here, the species chosen is a non-edible marine shell with either decorative 
properties or a ready made capacity for threading. In addition, the uniformity in taxa and size indicates that shells appropriated for ornamental purposes have been carefully selected and, it is worth noting, that these two characteristics are also reported for the MSA Blombos Cave beads (d'Errico et al. 2005: 18). Second, the effort and skill required for cutting and/or boring and smoothing the shells should not be overlooked. Cutting or boring a hole in a shell without breaking it is no easy task and in attempts made to duplicate shell beads described here, the incidence of breakage was frustratingly high. Third, the extent of standardisation in the manufacture of both the Riwi and Mandu Mandu Creek beads is striking. Metric data from both show a very homogeneous size distribution, and it is evident that within each group of beads, shells were being processed and deliberately modified by a variety of manufacturing techniques to conform to a predetermined style.

Both sets of beads were transported. At Cape Range peninsula, shells collected from the coast were taken to a shelter at least 3-5km from the shore. In the Kimberley region they were transported over a distance of some $300-500 \mathrm{~km}$. Two alternatives need to be considered in their transportation as unmodified or as finished objects - the shells selected for bead manufacture were either transported or they were exchanged. There are no unmodified shells at Riwi but the presence of one unmodified, very small cone shell at Mandu Mandu Creek rockshelter suggests that these shells may have been modified as beads on site. This rockshelter is, however, within easy walking distance from the shell source. Given the skills required in their manufacture it is likely that a substantial number of shells would be required in order to make a strand of beads. Thus, manufacturing beads in proximity to a ready source of shells - i.e. on the coast - would seem to be much more economical in terms of effort and frustration.

The Kimberley shells are amongst the earliest evidence for the long distance procurement of raw materials in Australia and in this context it is interesting that the exotic items are decorative objects. It is possible that their manufacturers carried the beads inland and, if this is so, it indicates very wide movement in the Pleistocene. The alternative is that the beads were exchanged supporting previous suggestions for pearl shell trade in the Kimberley by 19000 BP (O'Connor 1999: 121).

Brumm and Moore's (2005) recent review of the evidence for symbolic activity in the Australian archaeological record argues that, although there are some geographically and chronologically isolated Pleistocene examples of symbolic activity, an explosion of explicitly symbolic behaviour like that seen in the Upper Palaeolithic of Europe (Henshilwood \& Marean 2003; Mellars 2005) is not evident until the middle to late Holocene. Thus Brumm and Moore (2005: 168) suggest that the arguments linking the increased use of ornaments and exchange over long distances to the decreased social isolation in the Upper Palaeolithic of Europe (White 1982) are also appropriate for the Australian middle to late Holocene. In these arguments regional patterns in symbolic behaviour associated with the explosion are seen as a means of group identity.

If the beads discussed here pre-date the establishment of regional patterns in symbolic behaviour, they were presumably used to convey self identity or as social markers within the local group. There are many examples in recent Australian ethnohistoric source that Aboriginal people often wore beads in circumstances in which everyone was known by the wearer. For example, Roth (1897: 111) records necklaces made of grass beads as being 
worn as a symbol of Aboriginal men and women who have passed through the first stage of initiation in north-central Queensland.

What is difficult to explain is why people chose beads transported from such a long distance for these purposes. Presumably other ornaments, including beads, were constructed from local materials such as grass and seeds that have not survived in the archaeological record. Perhaps marine shell beads were more prestigious than ornaments made from readily available material. Whatever their use, the evident selection of raw material and transportation associated with the shell beads indicates the presence of wide networks in the early human occupation of Australia.

Although the trade and exchange of beads does not necessarily imply that the beads' meanings were shared between the groups involved in the transactions, the existence of exchange networks is important for maintaining relations between groups. It is interesting that the choice of raw material for this exchange is marine shell. Fragments of freshwater mussel are present throughout the Riwi sequence but none have evidence of modification. Land snails are also available in the area. The evident disregard for this locally available shell material implies that it was the marine source of the shell that was of some significance. It is not clear why, but perhaps maintenance of networks to coast was important in new environments especially at a time of increasing aridity.

\section{Acknowledgements}

We would like to thank the Aboriginal communities who allowed this work - in the Kimberley the Mimbi community especially the senior custodians Morgal and Neville Sharpe, and in the Cape Range Syd Dale and Mary and George Cooyou (both deceased) of the Kuwinywardu Aboriginal Corporation (now the Gnulli Working Group). For discussions on making dentalium beads with Min Smith and Kate Morse we thank Esther Paddy and Audaby Jack (both deceased) of the Djarindjin Community, Dampierland Peninsula. We would also like to thank Min Smith for telling us about this work and, with Ross Chadwick, for arranging access to the Western Australian Museum collections. George Kendrick and Shirley Slack Smith of the Western Australian Museum identified the shell species. Mark Harvey of the Western Australian Museum and David Haig of the University of Western Australia provided photographic advice. Vicky Winton drew figures 1 and 3 . Sandra Bowdler and Alice Gorman read a draft of this paper and we thank them for their comments.

\section{References}

Aмвrose, S.H. 1998. Chronology of the Later Stone Age and food production in east Africa. Journal of Archaeological Science 25: 377-92.

BALME, J. 2000. Excavation revealing 40000 years of occupation at Mimbi Caves, south central Kimberley, Western Australia. Australian Archaeology 51: 1-5.

BaLme, J. \& S. Bowdler. In press. Spear and digging stick: the origin of gender and its implications for the colonization of new continents. Journal of Social Archaeology 6(3): 379-401.

Bar-Yosef Mayer, D.E. 2005. The exploitation of shell beads in the Palaeolithic and Neolithic of the Levant. Paléorient 31: 176-85.
Bowler, J.M. \& A.G. ThORNE. 1976. Human remains from Lake Mungo: Discovery and excavation of Lake Mungo III, in R.L. Kirk \& A.G. Thorne (ed.) The Origin of the Australians: 127-38. Canberra: Australian Institute of Aboriginal Studies.

Bowler, J.M., R. Jones, H. Allen \& A.G. Thorne. 1970. Pleistocene human remains from Australia: a living site and human cremation from Lake Mungo, western New South Wales. World Archaeology 2: 39-60.

Brumm, A. \& M. Moore, 2005. Symbolic revolutions and the Australian archaeological record. Cambridge Archaeological Journal 15: 157-75. 


\section{Shell beads and social behaviour in Pleistocene Australia}

Conard, N.J. \& M. Bolus. 2003. Radiocarbon dating and the appearance of modern humans and timing of cultural innovations in Europe: new results and new challenges. Journal of Human Evolution 44: 332-71.

Davidson, I. \& W. Noble. 1992a. Why the first colonisation of the Australian region is the earliest evidence for modern human behaviour. Archaeology in Oceania 27: 135-42.

-1992b. Language gap. Nature 355: 403-4.

DeBÉNeTH, A. 1994. L'Arérien du nord de l'Afrique du Sahara. Sabara 6: 21-30.

d'Errico, F., C. Henshilwood, M. Vanhaeren \& K. VAN Niekerk. 2005. Nassarius karassianus shell beads from Blombos Cave: evidence for symbolic evidence in the Middle Stone Age. Journal of Human Evolution 48: 3-24.

Dortch, C. 1979. Australia's oldest known ornaments. Antiquity 53: 39-43.

Gamble, C. 1999. The Palacolithic Societies of Europe Cambridge: Cambridge University Press.

Hensullwood, C. \& C. Marean. 2003. The origin of modern human behaviour: critique of the models and their test implications. Current Anthropology 44 (5): 627-51.

Henshilwood, C., F. d'Errico, M. Vanhaeren, K. van Niekerk \& Z. Jacobs. 2004. Middle Stone Age shell beads from South Africa. Science 304 (5669): 404

Hiscock, P. \& L. WAllis. 2004. Pleistocene settlements of deserts from an Australian perspective, in P. Veth, M. Smith \& P. Hiscock (cd.) Desert Peoples: Archaeological Perspectives: 34-57. Oxford: Blackwell.

Kozıowsкi, J.K. 2000. The problem of cultural continuity between the middle and Upper Palaeolithic in central and eastern Europe, in O. Bar-Yosef, \& D. Pilbeam (ed.) The Geography of Neandertals and Modern Humans in Europe and the Greater Mediterranean: 77-106. Cambridge (MA): Peabody Museum Bulletin 8, Harvard University.

Kuhn, S.L., M.C. Stiner, D.S. Reese \& E. Gulec. 2001. Ornaments of the earliest Upper Palaeolithic: New insights from the Levant. Proceedings of the National Academy of the Sciences of the United States of America 98 (13): 7641-6.

McBreaty, S. \& A.S. Brooks. 2000. The revolution that wasn't: a new interpretation of the origin of modern human behaviour. Journal of Human Evolution 39: 453-563.

Mellars, P. 2005. The impossible coincidence. A single-species model for the origins of modern human behaviour in Europe. Evolutionary Anthropology 14: 12-27.
Morse, K. 1993. Shell beads from Mandu Mandu Creek rock-shelter, Cape Range Peninsula, Western Australia, dated before 30000 BP. Antiquity 67: 877-83.

O'Connell, J.F. \& F.J. Allen. 1998. When did humans first arrive in Greater Australia, and why is it important to know? Evolutionary Anthropology 6: 132-46.

O'Connor, S. 1995. Carpenter's Gap rockshelter I: 40000 years of Aboriginal occupation in the Napier Ranges, Kimberley, WA. Australian Archaeology 40: 58-9.

-1999. 30000 Years of Aboriginal Occupation: Kimberley, North West Australia. Canberra: Department of Archaeology and Natural History and Centre for Archaeological Research, Australian National University

O’Connor, S. \& B. Fankhauser. 2001. One step closer: an ochre covered rock from Carpenter's Gap Shelter 1, Kimberley region, Western Australia, in A. Anderson, I. Lilley \& S. O'Connor (ed.) Histories of Old Ages: Essays in Honour of Rhys Jones: 287-300. Canberra: Centre for Archaeological Research and Pandanus Books, The Australian National University.

O'Connor, S. \& P. Veth. 2006. Revisiting the past: Changing interpretations of Pleistocene settlement, subsistence and demograpahy in northern Australia, in I. Lilley (ed.) Archaeology of Oceania: Australia and the Pacific Islands: 31-47. Malden (MA): Blackwell.

Roberts, R.G., R. Jones \& M.A. SMITH. 1994. Beyond the radiocarbon barrier in Australian prehistory. Antiquity 68: 611-6.

Roth, W.E. 1897. Ethnological Studies Among the North-West-Central Queensland Aborigines. Brisbane: Edmond Gregory Government Printer.

SALI, S.A. 1989. The Upper Palaeolithic and Mesolithic cultures of Mabarashtra. Pune: Deccan College Post Graduate and Research Institute.

Shennan, S, 2001. Demography and cultural innovation: a model and its implications for the emergence of modern human culture. Cambridge Archaeological Journal 11(1): 5-16.

Stiner, M. 1999. Palaeolithic mollusc exploitation at Riparo Mochi (Balzi Rossi, Italy): food and ornaments from the Aurignacian through Epigravettian. Antiquity 73: 735-54.

STRINGER, C. 2001. Modern human origins distinguishing the models. African Archaeological Review 18(2): 67-75.

TABorin, Y. 1993. Shells of the French Aurignacian and Périgordian, in H. Knecht, A. Pike-Tay \& R. White (ed.) Before Lascaux: The complex record of the Early Upper Palaeolitbic: 211-27. Boca Raton: CRC Press. 
Taborin, Y. 2003. La mer et les premiers hommes modernes, in B. Vandermeersch (ed.) Echanges et diffusion dans la prébistoire méditeranéenne: 113-21. Paris: Editions du Comité des travaux histroriques et scientifiques.

VAnhaeren, M. \& F. D'Errico. 2003. Childhood in the Epipalaeolithic. What do personal ornaments associated with burials tell us?, in L. Larsson, H. Kindgren, K. Knutsson, D. Leoffler \& A. Akerlund (ed.) Mesolithic on the Move: Papers presented at the 6th International Conference on the Mesolithic in Europe, Stockholm 2000: 494-505. Oxford: Oxbow.

Vanhaeren, M., F. d'Errico, C. Stringer, S.L. James, J.A. Todd \& Henk K. Mienis. 2006. Middle Paleolithic shell beads in Israel and Algeria. Science 312: 1785-8.

Wells, F.E. \& C.W. Bryce. 2000. Seashells of Western Australia. Perth: Western Australian Museum.

Whrte, R. 1982. Rethinking the middle/upper Palaeolithic transition. Current Anthropology 23: 169-92.

-1989. Production complexity and standardisation in Early Aurignacian Bcad and Pendant manufacture: Evolutionary implications, in P. Mellars \& C. Stringer (ed.) The Human Revolution. Behavioural and Biological Perspectives on the Origins of Modern Humans: 366-90. Edinburgh: Edinburgh University Press.
-1992. Bcyond art: Toward an understanding of the origins of material representation in Europe. Annual Review of Anthropology 21: 537-64.

-1993 . Technological and social dimensions of 'Aurignacian-Age' body ornaments across Europe, in H. Knecht, A. Pike-Tay \& R. White (ed.) Before Lascaux: The complex record of the Early Upper Palaeolithic: 277-99. Boca Raton: CRC Press.

Wовsт, H.M. 1977. Stylistic Behavior and Information Exchange, in C.E. Cleland (ed.) Papers for the Director: Research essays in honour of James $B$. Griffen: 317-42. Ann Arbor: Museum of Anthropology/University of Michigan Press.

ZiLhấ, J. \& F. D'ERrico. 2003. The chronology of the Aurignacian and transitional technocomplexes. Where do we stand?, in J. Zilhâo \& F. d'Errico (cd.) The Chronology of the Aurignacian and of the Transitional Technocomplexes. Dating, Stratigraphies, Cultural Implications: 313-49. Lisbon: Insituto Português de Arqueologia. 